\title{
Alterações no teores de nutrientes em dois solos alagados, com e sem plantas de arroz
}

\author{
Nutrients concentration changes in two flooded soils during the rice cycle
}

\author{
Leandro Souza da Silva1 ${ }^{1}$ Rogério Oliveira de Sousa ${ }^{2}$ Humberto Bohnen ${ }^{3}$
}

\section{RESUMO}

$O$ alagamento e a presença de plantas alteram as propriedades biológicas e químicas do solo em relação ao ambiente anteriormente oxidado, influenciando a disponibilidade de nutrientes. Foi conduzido um experimento com o objetivo de avaliar as alterações dos teores de alguns nutrientes na solução de um Planossolo e um Gleissolo durante o ciclo do arroz. Os solos foram acondicionados em vasos (50 litros) contendo dispositivos para coleta da solução em diferentes profundidades, mantidos sem ou com plantas de arroz. A solução foi coletada aos 10, 19, 44, 77 e 113 dias de alagamento e determinados os teores de $\mathrm{P}, \mathrm{K}, \mathrm{Ca}, \mathrm{Mg}, \mathrm{Fe} e$ $\mathrm{Mn}$. A concentração dos nutrientes na solução, especialmente o $K$, variou com a profundidade de coleta e com a presença de plantas, demonstrando a influência desses fatores na disponibilidade dos nutrientes em solos alagados.

Palavras-chave: solução do solo, arroz, nutrientes.

\section{ABSTRACT}

Flooding a soil and growing plant on it can change its biological and chemistry properties, in comparison with a non-flooded environment. An experiment was conducted in order to study the nutrients dynamics in the solution of two soils (Planossolo and Gleissolo) during the rice cycle. Rice plants were cultivated in $50 L$ containers having devices to collect soil solution at several depths $(2.5,5.0,7.5$ and $31 \mathrm{~cm})$. In the soil solution, with and without plant, $P, K, C a, M g, F e$ and $\mathrm{Mn}$, were measured at 10, 19, 44, 77, and 113 days after the flooding. Potassium was especially sensible to the rice plant and depth of sampling

Key words: soil solution, rice, nutrients.
Em áreas irrigadas por alagamento, após o consumo do oxigênio, os microrganismos anaeróbios passam a utilizar compostos oxidados do solo como receptores de elétrons. A partir de reações de redução, modifica-se o $\mathrm{pH}$ e aumenta a disponibilidade de vários elementos (PONNAMPERUMA, 1972). O Fe(III) e $\mathrm{Mn}(\mathrm{IV})$ dos óxidos são reduzidos para $\mathrm{Fe}^{+2}$ e $\mathrm{Mn}^{+2}$, aumentando sua concentração na solução (VAHL, 1991). O P, em função da adsorção específica na superfície dos óxidos, é liberado para a solução na medida em que há redução do Fe estrutural (VAHL, 1999). O Ca, Mg e o K, embora não estejam diretamente envolvidos nas reações de oxirredução, também tem seus teores alterados, pois são deslocados dos sítios de troca pelo $\mathrm{Fe}^{2+}$ e $\mathrm{Mn}^{+2}$ (VAHL, 1991).

Embora sejam as características do solo que determinam a intensidade das modificações na solução, a presença de plantas determinará alterações no processo, quer pela absorção dos nutrientes, quer por modificações na rizosfera, principalmente devido ao fluxo de oxigênio nos aerênquimas e a precipitação do Fe nas raízes. O objetivo deste trabalho foi avaliar as alterações nos teores de alguns nutrientes na solução de solos alagados, em diferentes profundidades, durante o ciclo do arroz.

Foram utilizadas amostras de dois solos, coletados na camada de 0 a $20 \mathrm{~cm}$ no IRGA em Cachoeirinha-RS (Gleissolo) e em uma lavoura em Barra

\footnotetext{
${ }^{1}$ Engenheiro Agrônomo, Doutor, Professor Adjunto, Departamento de Solos, Centro de Ciências Rurais, Universidade Federal de Santa Maria, 97105-900, Santa Maria, RS. E-mail: Leandro@smail.ufsm.br. Autor para correspondência.

${ }^{2}$ Engenheiro Agrônomo, Doutor, Professor da Faculdade de Agronomia Eliseu Maciel, Universidade Federal de Pelotas. ${ }^{3}$ Engenheiro Agrônomo, PhD., colaborador convidado do Departamento de Solos, Faculdade de Agronomia, Universidade Federal do Rio Grande do Sul. Consultor do IRGA.
} 
do Ribeiro-RS (Planossolo). As amostras foram secas ao ar, destorroadas, peneiradas em malha de $4 \mathrm{~mm}$ e receberam adubação com $\mathrm{P}\left(0,26 \mathrm{~g} \mathrm{~kg}^{-1}\right.$ de SFT) e K $\left(0,1 \mathrm{~g} \mathrm{~kg}^{-1}\right.$ de $\left.\mathrm{KCl}\right)$, conforme análise do solo (Planossolo com $\mathrm{pH}$ (água) $=4,5 ; \mathrm{P}=12 \mathrm{mg} \mathrm{L}^{-1} ; \mathrm{K}=93 \mathrm{mg}$ $\mathrm{L}^{-1} ; \mathrm{m} .0 .=21 \mathrm{~g} \mathrm{~kg}^{-1} ; \mathrm{Ca}=0,6 \mathrm{cmol}_{\mathrm{c}} \mathrm{L}^{-1} ; \mathrm{Mg}=0,3 \mathrm{cmol}_{\mathrm{c}} \mathrm{L}^{-1}$; $\mathrm{Al}=1,2 \mathrm{cmol}_{\mathrm{c}} \mathrm{L}^{-1}$ e $\operatorname{argila}=150 \mathrm{~g} \mathrm{~kg}^{-1}$; Gleissolo com $\mathrm{pH}$ (água) $=5,0 ; \mathrm{P}=44 \mathrm{mg} \mathrm{L}^{-1} ; \mathrm{K}=52 \mathrm{mg} \mathrm{L}^{-1} ; \mathrm{m} .0 .=17 \mathrm{~g} \mathrm{~kg}^{-1}$; $\mathrm{Ca}=2,3 \mathrm{cmol}_{\mathrm{c}} \mathrm{L}^{-1} ; \mathrm{Mg}=0,6 \mathrm{cmol}_{\mathrm{c}} \mathrm{L}^{-1} ; \mathrm{Al}=0,4 \mathrm{cmol}_{\mathrm{c}} \mathrm{L}^{-1} \mathrm{e}$ argila $=170 \mathrm{~g} \mathrm{~kg}^{-1}$ ). Cada solo foi acondicionado em 2 vasos de cimento amianto com $50 \mathrm{~L}$, revestidos com resina acrílica, nos quais foram colocados 5 dispositivos para coleta da solução do solo no centro de cada vaso e nas profundidades de 2,5; 5,0; 7,5; 15,5 e $31 \mathrm{~cm}$ da superfície. O dispositivo foi construído com cano de PVC com $25 \mathrm{~mm}$ de diâmetro e $40 \mathrm{~mm}$ de comprimento, recoberto nas extremidades com tela de nylon (malha 100) e conectado a um cano de vidro cuja abertura na superficie era vedada com silicone. O alagamento completo dos vasos foi estabelecido com uma lâmina de água destilada de $5 \mathrm{~cm}$ sendo, aos cinco dias após o alagamento, transplantadas quatro plântulas de arroz (cultivar BR-IRGA 410) em um dos vasos de cada solo, mantendo-se o outro sem plantas.

Através de sucção na extremidade do cano de vidro, foram coletados $15 \mathrm{ml}$ da solução, de cada profundidade, aos 10, 19, 44, 77, e 113 dias de alagamento. Nas amostras de solução, foi adicionado $\mathrm{HCl} 1 \mathrm{~mol} \mathrm{~L}^{-1}$ e determinados os teores de $\mathrm{K}$ (fotômetro de chama), $\mathrm{Ca}, \mathrm{Mg}$, Fe e Mn (absorção atômica), e P (MURPHY \& RILEY, 1962), este após filtragem da solução em filtro $0,45 \mu \mathrm{m}$.
A concentração dos nutrientes avaliados aumentou com a profundidade de amostragem para os dois solos (Figuras 1 e 2). Este comportamento deve estar relacionado com a taxa de difusão do oxigênio no perfil do solo alagado e a atividade dos microrganismos redutores de $\mathrm{Fe}$. Apesar da difusão do $\mathrm{O}_{2}$ ser cerca de 10.000 vezes mais lenta na água do que no ar (PONNAMPERUMA, 1972), pode-se encontrar oxigênio difundido nos primeiros centímetros da superfície do solo (SHU-ZHENG, 1985). Assim, com maior disponibilidade de oxigênio, menor é a intensidade da redução e, conseqüentemente, menor liberação de Fe para a solução (Figura 1c), e menor o efeito deste sobre os teores dos outros elementos que são indiretamente afetados pela redução. Como os efeitos
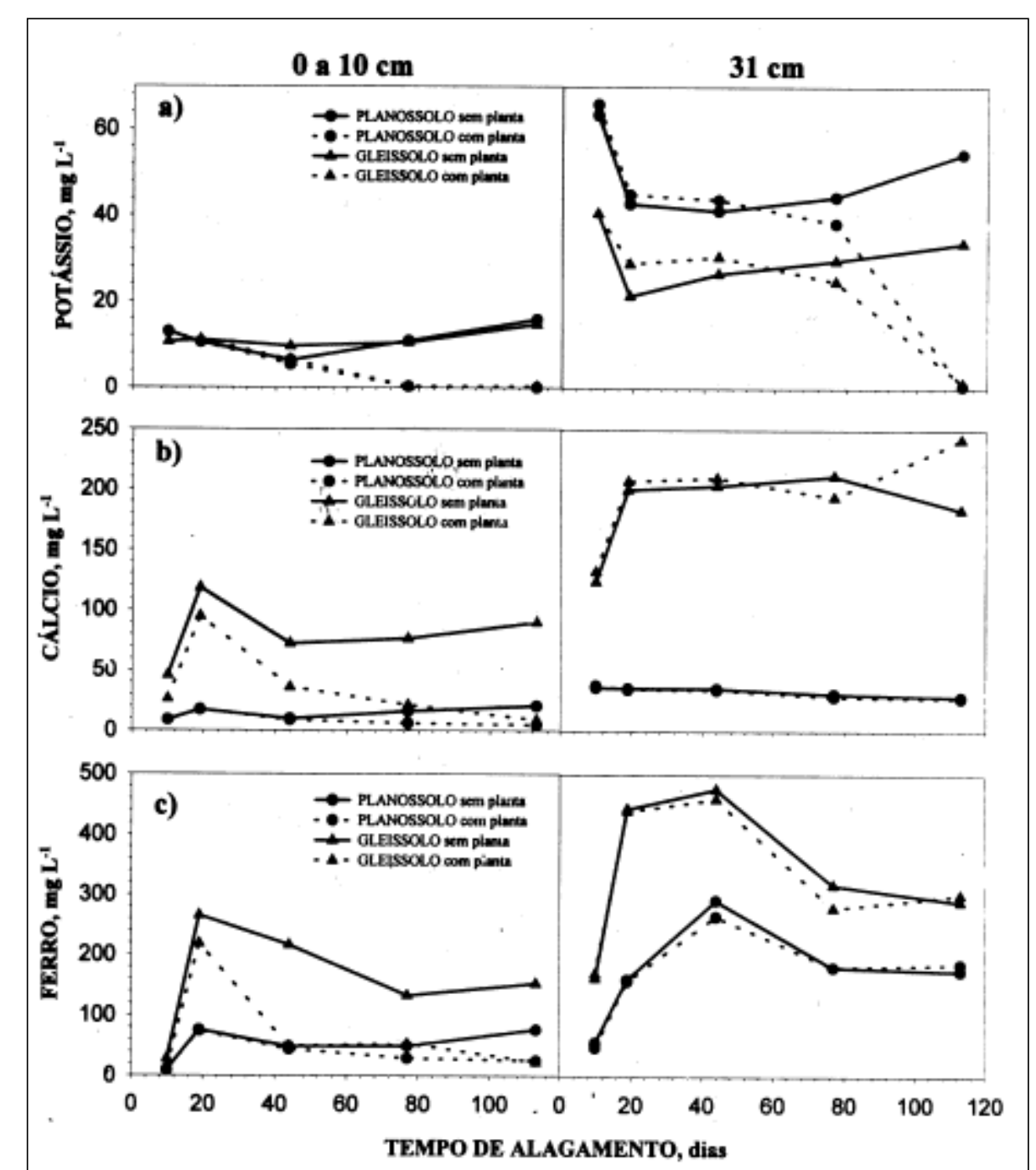

Figura 1 - Teores de potássio (a), cálcio (b) e ferro (c) na solução do solo em Planossolo e Gleissolo, com e sem planta, em função do tempo de alagamento e na média dos coletores da camada de 0 a $10 \mathrm{~cm}$ e aos $31 \mathrm{~cm}$ de profundidade. 

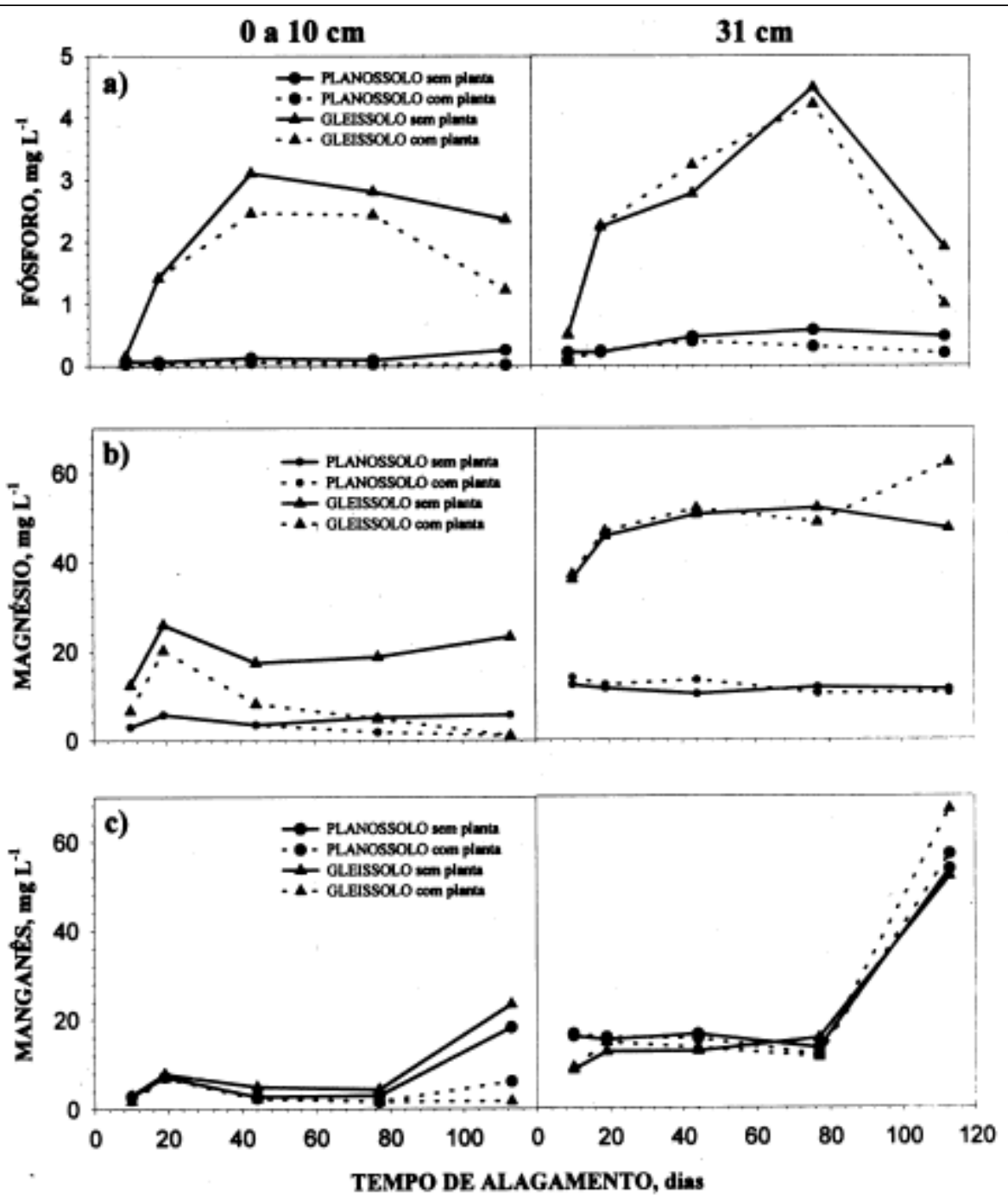

Figura 2 - Teores de fósforo (a), magnésio (b) e manganês (c) na solução do solo em Planossolo e Gleissolo, com e sem planta, em função do tempo de alagamento e na média dos coletores da camada de 0 a $10 \mathrm{~cm}$ e aos $31 \mathrm{~cm}$ de profundidade.

do alagamento sobre os teores dos nutrientes na solução dependem da composição do solo, os teores de $\mathrm{Fe}, \mathrm{Ca}, \mathrm{Mg}$ e $\mathrm{P}$ na solução foram diferentes entre os dois solos nas duas profundidades avaliadas.

A presença de plantas de arroz reduziu a concentração de todos os elementos avaliados na camada de 0 a $10 \mathrm{~cm}$ (Figuras 1 e 2). Assim, o efeito sobre a dinâmica dos nutrientes nesta camada deve estar diretamente relacionado com a absorção pelas raízes das plantas e a difusão do oxigênio pelos aerênquimas. Somente o $\mathrm{K}$ teve a sua concentração reduzida na camada de $31 \mathrm{~cm}$ de profundidade na presença de plantas (Figura 1a). Este fenômeno observado, juntamente com a contribuição do K nãotrocável, K na água de irrigação e a substituição parcial de K por Na, relacionados por CASTILHOS (1999), podem ajudar a explicar uma eventual falta de resposta à adubação com $\mathrm{K}$ em solos que as interpretações atuais da análise para a camada de 0 a $20 \mathrm{~cm}$ recomendam a aplicação de K.

De maneira geral, a concentração dos nutrientes na solução do solo, especialmente do K, variou com a profundidade de coleta e com a presença de plantas, demonstrando a influência desses fatores na disponibilidade dos nutrientes em solos alagados.

\section{REFERÊNCIAS BIBLIOGRÁFICAS}

CASTILHOS, R.M.V. Suprimento de potássio em solos cultivados com arroz irrigado e sua relação com 
mineralogia, formas e cinética de liberação. 1999. $175 \mathrm{f}$. Tese (Doutorado em Ciência do Solo) - Programa de Pósgraduação em Ciência do Solo, Universidade Federal do Rio Grande do Sul.

MURPHY, J.; RILEY, J.P. A modified single solution method for the determination of phosphate in natural waters. Analyt Chim Acta, Amsterdan, v.27, p.31-36, 1962.

PONNAMPERUMA, F.N. The chemical of submerged soils. Advances in Agronomy, v.24, p.29-96. 1972.
SHU-ZHENG, P. Oxygen. In: TIAN-REN, Y., (ed). Physical chemistry of paddy soils. Hong Kong : C\&C, 1985. p.47-68.

VAHL, L.C. Toxidez de ferro em genótipos de arroz irrigado por alagamento. 1991. 173f. Tese (Doutorado em Ciência do Solo) - Programa de Pós-graduação em Agronomia, Universidade Federal do Rio Grande do Sul.

VAHL, L.C. Fertilidade de solos de várzea. In: GOMES, A.S.; PAUletto, E.A. (eds). Manejo do solo e da água em áreas de várzea. Pelotas : Embrapa Clima Temperado, 1999. p.119-162. 